\begin{tabular}{|c|l|}
\hline Title & Coupling of an individual-based model of anchovy with lower trophic level and hydrodynamic models \\
\hline Author(s) & Yuheng, Wang; Hao, Wei; Kishi, Michio J. \\
\hline Citation & Journal of Ocean University of China, 1211), 45-52 \\
\hline https://doi.org/10.1007/311802-013-1901-x
\end{tabular}

Instructions for use 


\section{Coupling of an Individual-based Model of Anchovy with Lower Trophic Level and Hydrodynamic Models}

Wang Yuheng'), Wei Hao ${ }^{2)}$, and Michio J. Kishi ${ }^{3)}$

1) Key Laboratory of Physical Oceanography, Ocean University of China, Qingdao 266100, P.R. China

2) College of Marine Science and Engineering, Tianjin University of Science and Technology, Tianjin 300457, P.R. China

3) Faculty of Fisheries Sciences, Hokkaido University, Hokkaido 060-0813, Japan

Abstract Anchovy (Engraulis japonicus), a small pelagic fish and food of other economic fishes, is a key species in the Yellow Sea ecosystem. Understanding the mechanisms of its recruitment and biomass variation is important for the prediction and management of fishery resources. Coupled with a hydrodynamic model (POM) and a lower trophic level ecosystem model (NEMURO), an individual-based model of anchovy is developed to study the influence of physical environment on anchovy's biomass variation. Seasonal variations of circulation, water temperature and mix-layer depth from POM are used as external forcing for NEMURO and the anchovy model. Biomasses of large zooplankton and predatory zooplankton which anchovy feeds on are output from NEMURO and are controlled by the consumption of anchovy on them. Survival fitness theory related to temperature and food is used to determine the swimming action of anchovy in the model. The simulation results agree well with observations and elucidate the influence of temperature in over-wintering migration and food in feeding migration. 
Key words anchovy; individual-based model; population dynamics; Yellow Sea

\section{Introduction}

Understanding the effect of physical environment on ecosystems is essential for developing quantitative approaches to sustainable fishery management. The physical environment can influence fish population by modifying lower trophic levels, altering fish bioenergetics and changing migration routes. Many efforts have been made to establish end-to-end ecosystem models (Megrey et al., 2007; Ito et al., 2007; Fulton, 2010) that make it possible to study the first and second effects mentioned above. IBM (Individual-Based Model) models were developed to study saury's response to the climate variation in the north Pacific (Ito et al., 2007). However, most of these models use a fixed migration route. While several migration models were built (Okunishi et al., 2009; Pershing et al., 2009), they were not coupled with lower trophic level models. In this study, an individual-based model is developed and coupled with low trophic level and hydrodynamic models for studying the influence of physical environment on anchovy population in the Yellow Sea (YS).

The YS, a semi-enclosed shelf sea in the North Pacific, provides a major over-wintering and feeding ground for numerous species of fish (Fig.1). The physical setting in the YS exhibits complicated spatial and temporal variations. In winter, a warm and salty water mass is present in the deep central trough. In summer, the deep layer below the thermocline is occupied by the Yellow Sea Cold Water, thus providing an over-summering site for many temperate species. The water temperature records in the YS suggest a regime shift occurring around 1986 (Wei et al., 2010). But the influence of this change on the ecosystem remains unknown.

Anchovy (Engraulis japonius) is a widely distributed pelagic fish species living in temperate seas. Before the initiation of a large-scale anchovy-targeted fishery in the early 1990s, anchovy was the 
most abundant fish species in the YS with a stock of around 3 million tons (Zhu and Iversen, 1990). Anchovy is important both as a prey species and as a major plankton feeder, hence plays a key role in the ecosystem of the YS (Wei and Jiang, 1992). Anchovy is also one of the extensively studied fish species in the YS. Studies on anchovy are important for the acquisition of bioenergetics parameters.

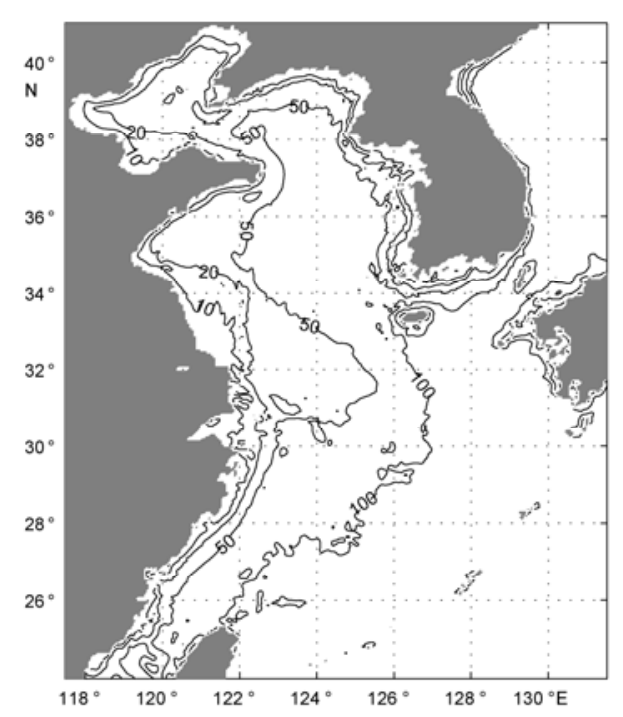

Fig.1 The study area with depth contours (m).

2 Model description 


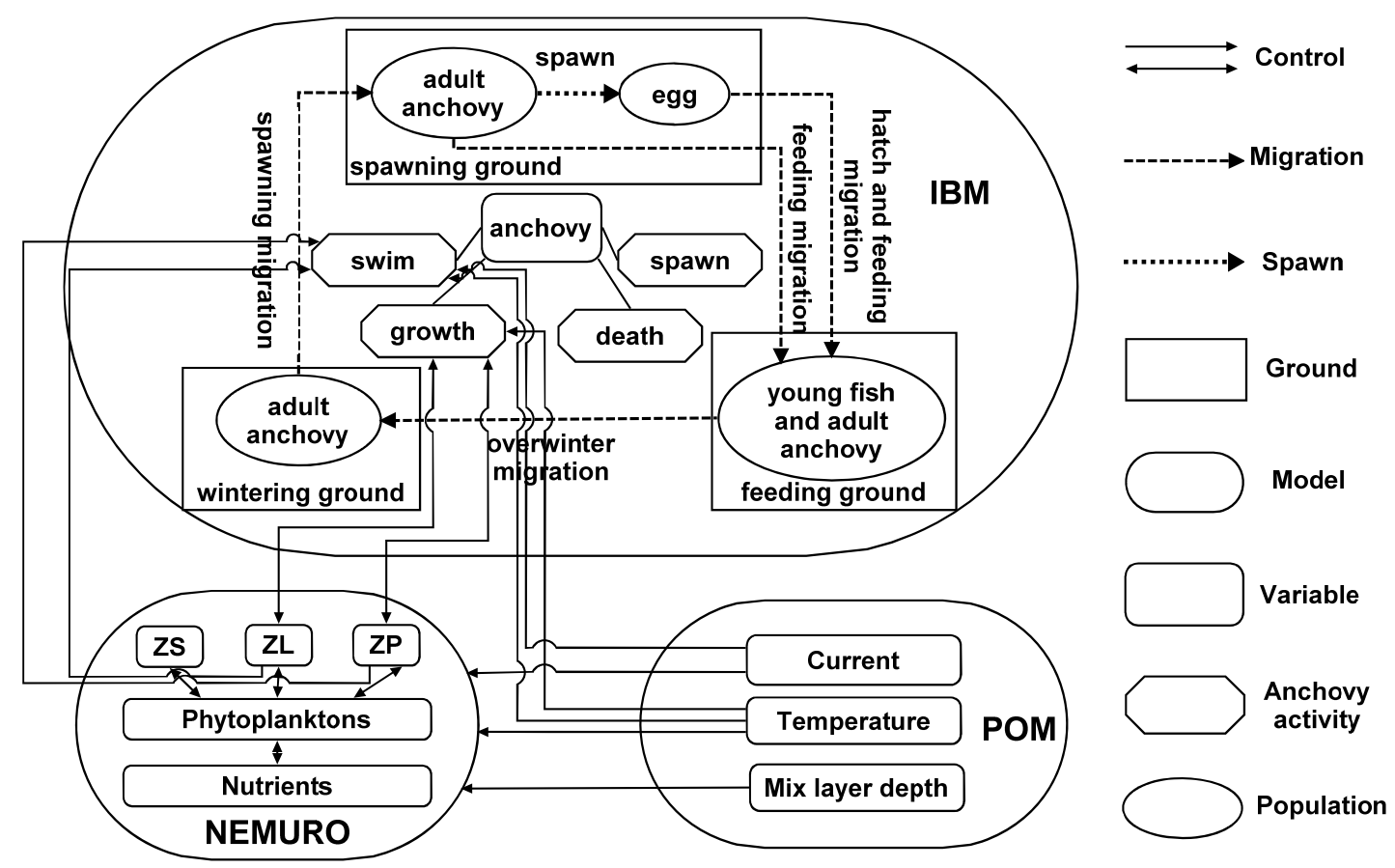

Fig.2 Framework of the coupled model.

The coupled model contains three components: a hydrodynamic model to provide physical forcing, a lower trophic level model to generate distributions of nutrients and planktons, and an IBM model to simulate the anchovy population dynamics (Fig.2). The hydrodynamic model was run in offline mode while the lower trophic level model and IBM were in online mode.

\subsection{POM}

The hydrodynamic model is based on the Princeton Ocean Model (POM). It is a three-dimensional primitive ocean model (Blumberg and Mellor, 1987; Mellor, 1998). The model has a horizontal resolution of $1 / 18^{\circ}$ in latitude/longitude, and 21 sigma layers in the vertical. POM provides mixed-layer depth, mixed-layer temperature and circulation as physical forcing to the ecosystem model (Guo et al., 2003). 


\subsection{NEMURO}

NEMURO (the North Pacific Ecosystem Model Used for Regional Oceanography) is a low trophic level ecosystem model developed by the model Task Team of the PICES CCCC (the North Pacific Marine Science Organization, Climate Change and Carrying Capacity) program (Kishi et al., 2007). It contains 11 state variables, including two kinds of phytoplankton (small phytoplankton, PS and large phytoplankton, PL) and three kinds of zooplankton (small zooplankton, ZS, large zooplankton, ZL, and predatory zooplankton, ZP). The model was originally used for the open ocean (North Pacific). The following modifications of the model were made for the YS. 1) The cycle of phosphate $\left(\mathrm{HPO}_{4}-\mathrm{P}\right.$, DOP (dissolved organic phosphorus) and POP (particulate organic phosphorus)) was added (Wang, 2007) considering that the growth of phytoplankton in the YS is mainly P-limited (Gao et al., 2004). 2) River and atmospheric inputs, the important sources of nutrients, were added. 3) The method proposed by Wei et al. (2002) was used to calculate the exchange of nutrients with the deeper ocean layer instead of using the fixed exchange rate in the original NEMURO. 4) The suspended particulate matter (SPM) was taken into account in the calculation of light intensity because of the high concentration of SPM in the YS.

\subsection{Fish bioenergetics}

The modeling of bioenergetics mainly follows the approach of Rudstam (1998) and Megrey and Kishi (2002). The growth of an individual anchovy is calculated using the following equation: $\frac{d W}{d t}=(C-R-S-E G-E X) W$

where $W$ is the wet weight $(\mathrm{g}) ; t$ is the time (s); $C, R, S, E G$ and $E X$ (all in unit of $\mathrm{s}^{-1}$ ) determine the rates for consumption, respiration, special dynamic action, egestion and excretion, respectively. . 


\subsection{Population dynamics model}

\subsubsection{Swimming}

The swimming speed $U_{s}$ is a function of fork length and temperature

$\left\{\begin{array}{ll}U_{s}=k_{v} \cdot L & \mathrm{~T} \geq \mathrm{T}_{s} \\ U_{s}=k_{v} \cdot L \cdot e^{r_{v}\left(T-T_{s}\right)} & \mathrm{T}<\mathrm{T}_{s}\end{array}\right.$,

$L=4.2845 \cdot W^{0.3798}$,

here $L$ is the characteristic fork length, calculated according to the equation proposed by Zhuang et al.(1997). The actual fork length in the model does not shrink with decreasing body weight. The swimming speed $U_{s}$ is proportional to $L$, with the parameter $k_{v}$ being a constant. $U_{s}$ is independent of temperature $(T)$ when $T$ is above a threshold value $\left(T_{s}\right)$, and decreases with decreasing temperature when $T$ is below $T_{s}$. Finally, $r_{v}$ is a scaling parameter in quantifying the influence of temperature on the swimming speed.

To represent the influence of environmental conditions on anchovy migration, a method based on survival fitness theory (Railsback, 2005) is employed in the model. At each time step, an anchovy can swim directionally or randomly. The possibility of directional swimming is related to the graduation of fitness function

$f=e^{\frac{\log h_{f}(T)+\log g(P)}{2}}$,

where the fitness function, $f$, shows the preference of anchovy to the environment. It depends on the temperature $(T)$ and the prey density $(P)$. The term $g(P)$ shows the effect of prey density on fitness and is the same as the one used in consumption, while $h_{f}(T)$ shows the effect of temperature on fitness and has the same form as $h_{C}(T)$ defined in Appendix A, but has a different set of coefficients $\left(t e 1_{f}, t e 2_{f}, t e 3_{f}, t e 4_{f}, x k 1_{f}, x k 2_{f}, x k 3_{f}\right.$, and $\left.x k 4_{f}\right)$ (see Appendix for details). 
The swimming direction is decided by the following equation:

$\begin{cases}\theta=\theta_{f} & R<\frac{\Delta f}{\Delta f+\Delta f_{h}}, \\ \theta=\operatorname{rand}(0,2 \pi) & R \geq \frac{\Delta f}{\Delta f+\Delta f_{h}}\end{cases}$

$R=\operatorname{rand}(0,1)$,

where $\operatorname{rand}(a, b)$ generates a random number of uniform distribution in the interval $(a, b) ; \Delta f$ is the horizontal gradient of the fitness; $\theta_{f}$ is the direction of $\Delta f$, with $\Delta f=|\Delta f| \exp \left(\sqrt{-1} \theta_{f}\right)$ and $\Delta f_{h}$ is the half saturation of $\Delta f$.

\subsubsection{Migration}

The motion of anchovy is a combination of swimming and passive drifting with current, hence $\vec{P}_{n+1}=\vec{P}_{n}+\left(\vec{v}_{c}+\vec{v}_{s}\right)_{t=n} \cdot \Delta t$, $\overrightarrow{v_{s}}=U_{s} e^{i \theta}$,

where $\vec{P}_{n}$ and $\vec{P}_{n+1}$ denote respectively the position of an anchovy at time step $n$ and $n+1, \vec{v}_{c}$ is the water velocity, $\vec{v}_{s}$ is the swimming velocity, and $\Delta t$ is the time step.

\subsubsection{Reproduction}

Anchovy is a multiple spawning pelagic species, maturing at a body length of about $8-9 \mathrm{~cm}$. The spawning season of anchovy extends from May to September. There are many spawn fields along the coast, but anchovy can spawn in the entire YS if environmental conditions are suitable (Zhu and Iversen, 1990; Zhao, 2006). In the model, anchovy will spawn 5 times from mid-May through September. Each time the number of eggs is calculated with the following procedures.

First, the total recruitment $(R)$ is calculated as a function of spawning stock biomass (SSB) according to Zhao et al. (2003), i.e. 
$R=a_{s} \cdot S S B \cdot e^{b_{s} \cdot S S B} \cdot r_{R 2 e g g}$,

$r_{R 2 e g g}=e^{\alpha_{0}\left(t-t_{0}\right)}$,

where $R$ is given in billion and $S S B$ in million ton, $a_{s}$ and $b_{s}$ are the non-dimensional parameters, $r_{R 2 e g g}$ is the transfer ratio, $t$ is the time in a spawn season, and $t_{0}$ is the time of the winter following the spawn season and starting from January 1 . Because the above equation was originally developed for the recruitment of the age- 1 anchovy, the mortality coefficient for the age- 0 anchovy is assumed as constant for the calculation of egg numbers.

Second, the recruitment for each region is calculated as $R_{i, j}=R \cdot \frac{S S B_{i, j}}{\sum_{i} S S B_{i, j}} \cdot \frac{W S_{i, j}}{\sum_{j} W S_{i, j}}$,

where $i$ and $j$ denote the region and time, respectively; $W s_{i, j}$ is the spawning weight in the region $i$ and at the spawn time $j$.

\subsubsection{Mortality}

The abundance of anchovy is denoted as $N_{t}$ and $N_{t+\Delta t}$ at the time $t$ and $t+\Delta t$, respectively, and $N_{t+\Delta t}=N_{t} e^{-\alpha_{i} \Delta t}$, where $\alpha_{\mathrm{i}}$ is the natural mortality coefficient for the age- $i$ anchovy. The mortality coefficient for the age-1+ anchovy was reported by Zhao et al. (2003). No observational data are available for the mortality coefficient of the age-0 Japanese anchovy (Engraulis japonicus). Therefore the mortality coefficient of the European anchovy (Engraulis encrasicolus) is used (Mantzounia, 2007).

\section{Results}

The model covers the Bohai Sea, the Yellow Sea and the East China Sea. The initial conditions of 
nutrients and planktons are taken from the Marine Atlas of the Bohai Sea, Yellow Sea and East China Sea (Editorial Board for Marine Atlas, 1991a, b). The values of the state variables (i.e. planktons and nutrients) at lateral open boundaries are fixed, being set the same as the initial conditions. This boundary specification is acceptable, because the open boundaries (at $130.61^{\circ} \mathrm{E}$ and $24.08^{\circ} \mathrm{N}$ ) are far away from the study area. For simulations, 500 schools of anchovy are put into the model on January 1 , each representing $6 \times 10^{8}$ anchovy. All the anchovy are supposed to be born on June 15 the previous year and are randomly distributed in the over-wintering ground. The model simulation was run for 9 years and the results for the last 4 years were analyzed.

\subsection{Growth}
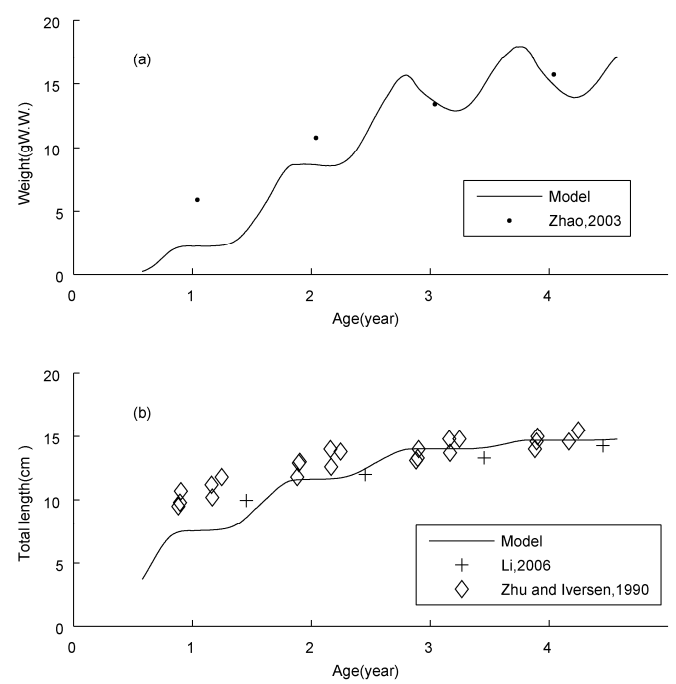

Fig. 3 The growth of anchovy as a function of (a) wet weight $(\mathrm{g})$ and (b) total length (cm). The model results and observations are represented by solid lines and different symbols, respectively.

The growth of anchovy from model simulation and observations are shown in Fig. 3Fig. 3. The model results and observations are in good agreement except for the age- 1 anchovy, both the calculated weight and total length of which are less than the observed values. There are two 
possible reasons for this discrepancy. First, some parameters for the age-1 anchovy are used in the place of the parameters for the age-0 anchovy because the later are unknown. Secondly, most of the observational data were collected from the over-wintering ground, the observations may overestimate the growth. Jin et al. (2005) reported the existence of the age-0 anchovy in the Bohai Sea in December. This suggests that anchovy with low swimming ability (usually with shorter total lengths and lighter weights) may not have been included in the datasets collected in over-wintering grounds (Zhao, 2006).

\subsection{Age structure}

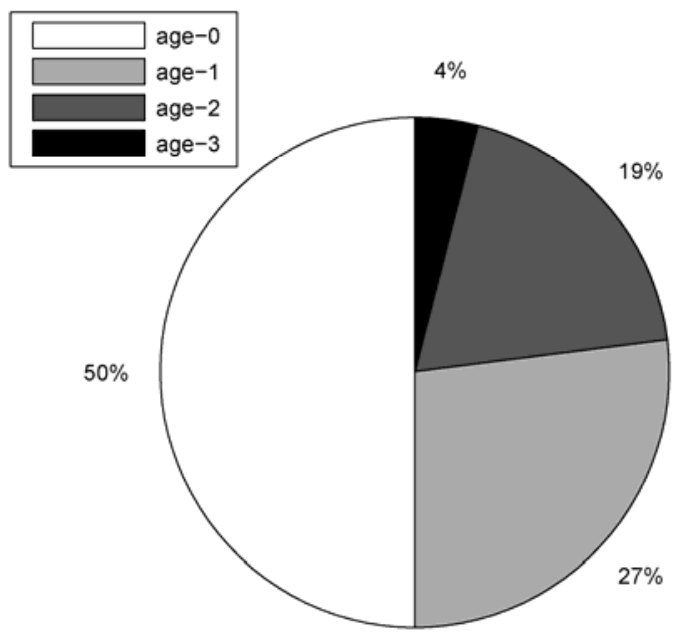

Fig. 4 The calculated age structure of the over-wintering stock.

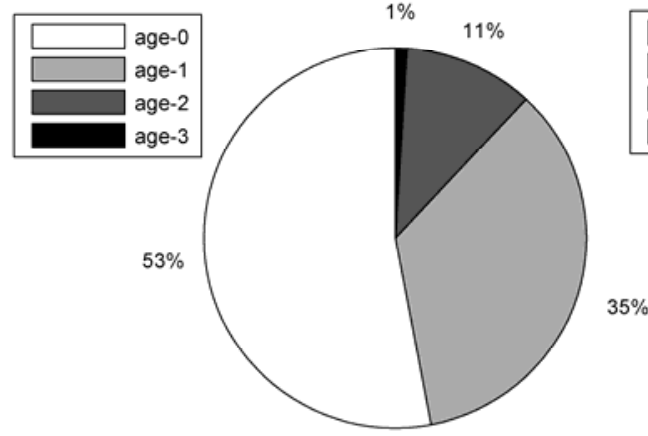

(a)

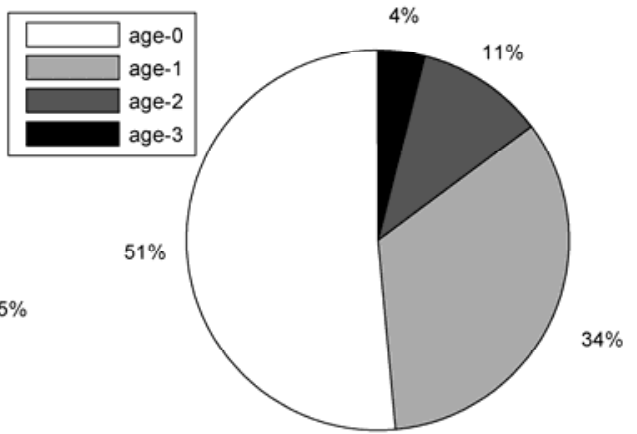

(b)

Fig. 5 The age structure of spawning stock from (a) observations (Li et al., 2006) and (b) model 
results.

Zhao (2006) analyzed the observed age structure of the over-wintering stocks from 1985 through 2005 and found a significant difference between those before and after the collapse of anchovy population in the late 1990s. As fishing is not taken into account in this model, only the data before the late 1990s are used. During this period, the age- 1 anchovy accounts for $30 \%-60 \%$ of the spawning stock, the age-2 20\%-50\%, the age-3 10\%-30\%, and the age-4 less than $10 \%$. The model results (Fig. 4Fig. 4) agrees with the observed values fairly well. The modeled age structure of the spawning stock in to the south of the Shandong Peninsula in the YS (Fig. 5b) generally agrees with the observed structure reported by Li et al. (2006) (Fig. 5a).

\subsection{Migration}
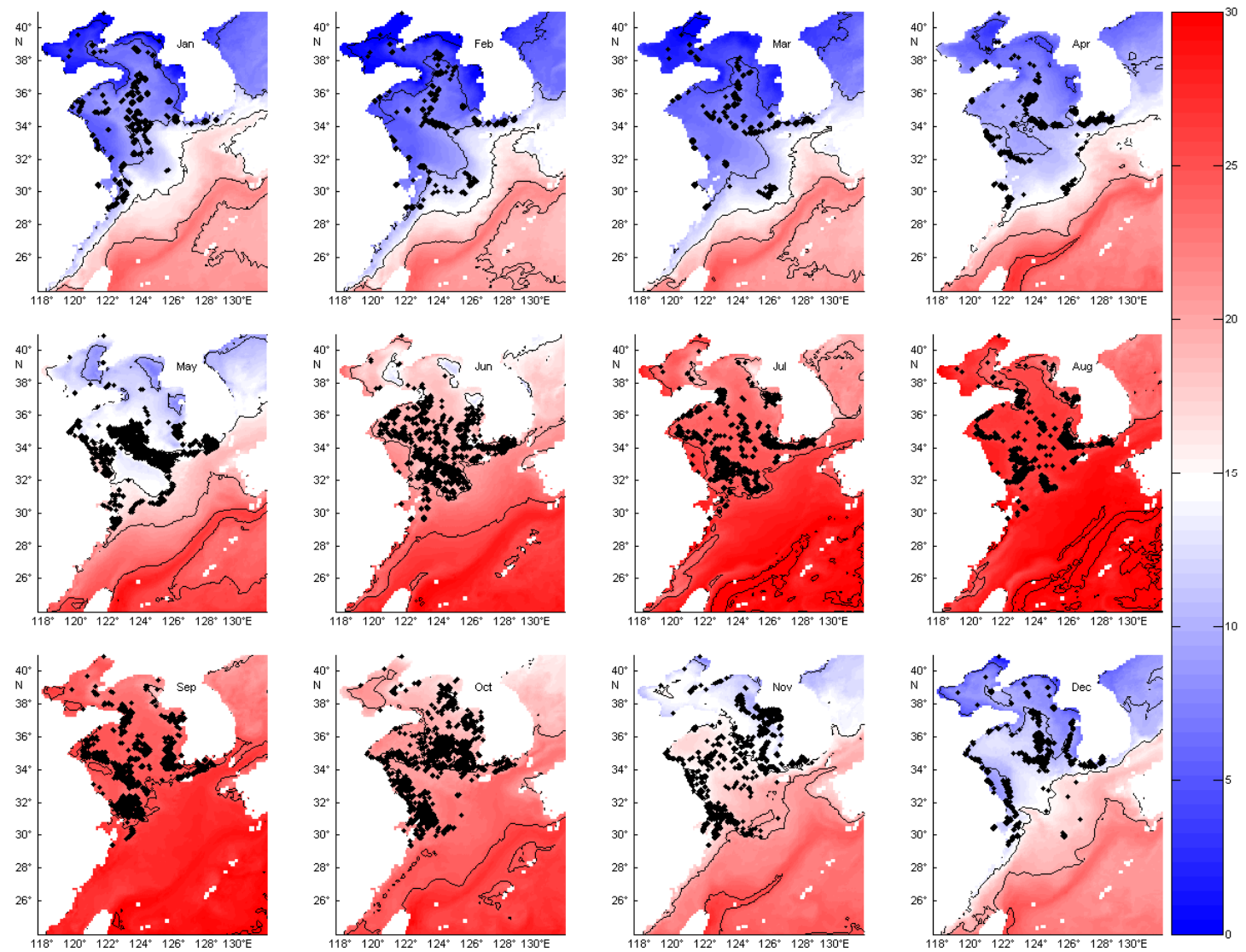
Fig.6 The migration of anchovy. Contour lines show the averaged mixed-layer temperature $\left({ }^{\circ} \mathrm{C}\right)$ and dots show the calculated positions of anchovy.

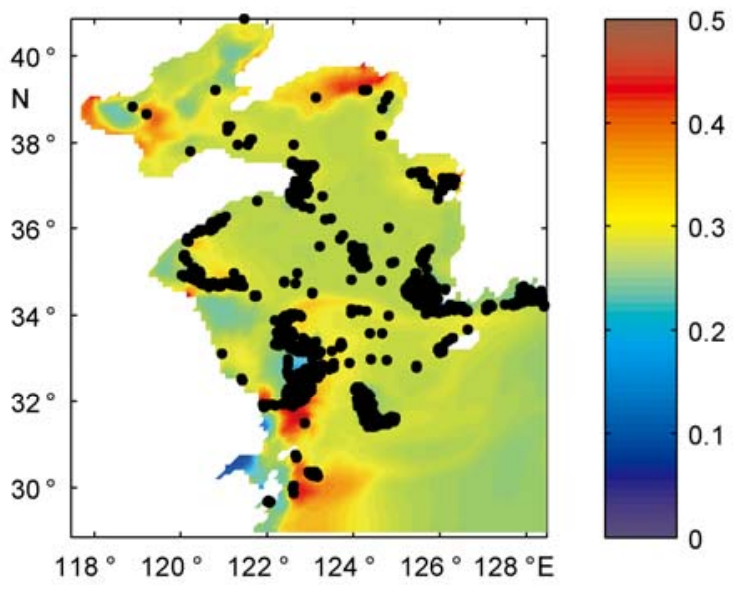

Fig.7 The relationship between the anchovy migration and the prey density. Contour lines show the prey density $(\mathrm{ZL}+\mathrm{ZP}, \mu \mathrm{molN} / \mathrm{L})$ and dots show the calculated positions of anchovy.

As seasons change, anchovy migrate for over-wintering, spawning and feeding in the YS (Zhu and Iversen, 1990; Zhao, 2006). From the late December to early February, most anchovy stay in the over-wintering grounds between the isothermal lines of $11^{\circ} \mathrm{C}$ and $13^{\circ} \mathrm{C}$. In the model, a large portion of anchovy stay in the over-wintering grounds, but a small portion is distributed along the coast and in the Bohai Sea. The spawning season is from May to October and reaches its peak between mid-May and late June. According to observations, anchovy start to move to the spawning ground in March. In the spawning fields off Chengshantou and in Haizhou Bay, abundant spawning anchovy are found in the model, especially in June, and some anchovy in the central and southern YS, which is consistent with the results of previous study (Li, 1987). In August and September, anchovy finish spawning and start to move back to deeper waters, while some smaller ones still stay in spawning fields. In October and November, most anchovy move to the central area of the southern YS. 
The model results show that migration is mainly controlled by temperature and prey density and anchovy are moving bewteen the isothermal lines of $11^{\circ} \mathrm{C}$ and $13^{\circ} \mathrm{C}$ (Fig. 6), suggesting that the influence of temperature is particularly important during winter. This aspect of model result is consistent with the analysis by Li (2006). Fig.7Fig.7 shows the biomass of prey species (ZL and ZP) and its relationship with the feeding migration. A large portion of the anchovy assembles in areas with high prey density (such as the outer zone of the Yangtze River estuary and the area to the south of the Shandong Peninsula), a clear demonstration of the importance of food in the feeding migration. Some anchovy also assemble in the areas around the Hupi Reef and to the southwest of the Korean Peninsula, where the prey density is not higher than that in the adjacent waters. By analyzing the productivity of prey species (Fig.8), high productivity is found in these areas. It seems that the feeding activity of the modeled anchovy accelerates the cycling of nutrients and results in high primary and secondary productivity. The assemblage of anchovy in those areas is primarily due to physical factors (temperature or circulation), and the high prey productivity in the area is of secondary importance.

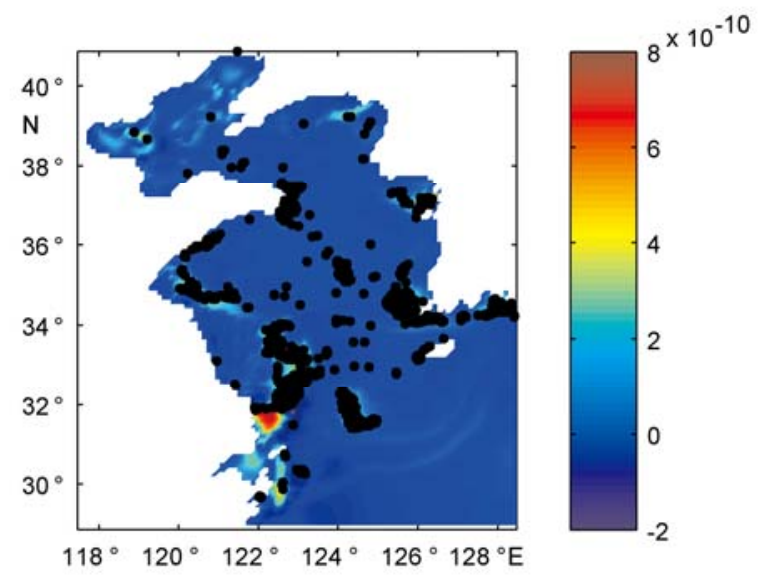

Fig. 8 The relationship between the anchovy migration and the prey productivity. Contour lines show the prey productivity $\left(\mathrm{ZL}+\mathrm{ZP}, \mu \mathrm{molN} \cdot \mathrm{L}^{-1} \cdot \mathrm{s}^{-1}\right)$ and dots show the position of the modeled anchovy. 


\section{Discussion and summary}

An individual-based model for anchovy, coupled with a low trophic level model and a hydrodynamic model, is developed and applied in the Yellow Sea. The model results of the growth and age structure show a good agreement with observations. The calculated pattern of the anchovy migration is also similar to that based on observations. The results suggest that water temperature is an important factor for the over-wintering migration while food is important for the feeding migration. Thus, it is essential to take both factors into account in a migration model.

Two issues remain to be resolved in the calculations. First, anchovy stay in the coastal area during the winter time, which is inconsistent with observations. Adding salinity into the fitness function may improve the model performance. Second, anchovy in the model seldom move through the Bohai Strait, which could be due to the over simplification of the migration mechanism adopted in the model. The modeled anchovy only perceive the environment at adjacent grids. If the environment is favorable to anchovy inside the Bohai Sea but not at the Bohai Strait, the anchovy outside will not migrate to the Bohai Sea through the Strait. Future resolution of those issues requires further understanding of the anchovy migration mechanism.

\section{Acknowledgements}

This work was supported by the National Natural Science Foundation of China (Grant No. 40830854) and the National Basic Research Program of China (Grant No. 2011CB403606). We are grateful to Prof. Guo Xinyu at Ehime University for providing POM output. We thank the four anonymous reviewers for their comments and suggestions.

\section{References}


Blumberg A. F., and G. L. Mellor, 1987. A description of a three dimensional coastal ocean circulation model.

Three-Dimensional Coastal Ocean Models, N. Heaps, Ed., Coastal and Estuarine Series, No. 4, American Geophysical Union, 1-16.

Editorial Board for Marine Atlas, 1991. Marine atlas of Bohai Sea, Yellow Sea and East China Sea (Chemistry). Beijing: China Ocean Press (in Chinese).

Editorial Board for Marine Atlas, 1991. Marine atlas of Bohai Sea, Yellow Sea and East China Sea (Biology). Beijing: China Ocean Press (in Chinese).

Fulton E. A., 2010. Approaches to end-to-end ecosystem models. Journal of Marine Systems, 81:171-183.

Gao S. Q., Y. A. Lin, M. M. Jin, and D. W. Gao, 2004. Distribution features of nutrients and nutrient structure in the East China Sea and the Yellow Sea in spring and autumn. Donghai Marine Science, 22(4):38-50 (in Chinese with English abstract).

Guo X. Y., H. Hukuda, Y. Miyazawa, and T. Yamagata, 2003. A Triply Nested Ocean Model for Simulating the Kuroshio—-Roles of Horizontal Resolution on JEBAR. Journal of Physical Oceanography, 33:146-169.

Ito S. I., B. A. Megrey, M. J. Kishi, D. Mukai, Y. Kurita, Y. Ueno, Y. Yamanaka, 2007. On the interannual variability of the growth of Pacific saury (Cololabis saira): A simple 3-box model using NEMURO.FISH. Ecological Modelling, 202:174-183

Jin X. S., X. Y. Zhao, and T. X. Meng, 2005. Biological resources and habitat environment of Bohai Sea and Yellow Sea. Beijing: Science Press(in Chinese).

Kishi M. J., M. Kashiwai, D. M. Ware, B. A. Megrey, D. L. Eslinger, F. E. Werner, M. Noguchi-Aita, T. Azumaya, M. Fujii, S. Hashimoto, D. J. Huang, H. Iizumi, Y. Ishida, S. Kang, G. A. Kantakov, H. Kim, K. Komatsu, V. V. Navrotsky, S. L. Smith, K. Tadokoro, A. Tsuda, O. Yamamura, Y. Yamanaka, K. Yokouchi, N. Yoshie, J. Zhang, Y. I. Zuenko, and V. I. Zvalinsky, 2007. NEMURO—a lower trophic level model for the North Pacific marine ecosystem. Ecological Modelling, 202:12-25. 
Li F. G.., 1987. Reproductive behavior of anchovy in middle and south Yellow Sea. Marine Fisheries Research, 8:41-50 (in Chinese).

Li X. S., X. Y. Zhao, F. Li, F. G. Li, Q. F. Dai, and J. C. Zhu, 2006. Structure and its variation of the anchovy (Engraulis japonicus) spawning stock in the Southern waters to Shandong Peninsula. Marine Fisheries Research, 27(1):46-53 (in Chinese with English abstract).

Li Y., 2006. Migration and Distribution of Anchovy in Yellow Sea and Its Relation with Environmental Factors. Master Dissertation. Qingdao: Ocean University of China, (in Chinese with English abstract).

Mantzounia I., S. Somarakis, D. K. Moutopoulos, A. Kallianiotis, and C. Koutsikopoulos, 2007. Periodic, spatially structured matrix model for the study of anchovy (Engraulis encrasicolus) population dynamics in $\mathrm{N}$ Aegean Sea (E. Mediterranean). Ecological Modelling, 208:367-377.

Megrey B. A., and M. J. Kishi, 2002. Model/REX workshop to develop a marine ecosystem model of the North Pacific Ocean including pelagic fishes. PICES Scientific Reports, 20:77-176.

Megrey B.A., K.A. Rose, R.A. Klumb, D.E. Hay, F.E. Werner, D.L. Eslinger, and S.L. Smith, 2007. Bioenergetics-based population dynamics model of Pacific herring (Clupea harenguspallasii) coupled to a lower trophic level nutrient-phytoplankton-zooplankton model: description, calibration and sensitivity analysis. Ecological Modelling, 202: 144-164.

Mellor G. L., User's guide for a three-dimensional, primitive equation, numerical ocean model. Rep., Program in Atmospheric and Oceanic Science, Princeton University, 1998.

Okunishi T., Y. Yamanaka, and S. Ito, 2009. A simulation model for Japanese sardine (Sardinops melanostictus) migrations in the western North Pacific. Ecological Modelling, 220: 462-479.

Pershing A. J., N. R. Record, B. C. Monger, C. A. Mayo, M. W. Brown, T. V. N. Cole, R. D. Kenney, D. E. Pendleton, and L. A. Woodard, 2009. Model-based estimates of right whale habitat use in the Gulf of Maine. 
Railsback S. F., B. C. Harvey, J. W. Hayse, and K. E. LaGory, 2005. Tests of theory for diel variation in salmonid feeding activity and habitat use. Ecology, 86(4): 947-959.

Rudstam L. G., 1988. Exploring the dynamics of herring consumption in the Baltic: applications of an energetic model of fish growth. Kieler Meeresforschung Sonderheft, 6:312-322.

Thornton, K. W., and A. S. Lessem, 1978. A temperature algorithm for modifying biological rates. Transactions of the American Fisheries Society, 107(2):284-287.

Wang Z, 2007. Modeling and analysis of the change of plankton ecosystem in Jiaozhou Bay for 40 years. Master Dissertation. Qingdao: Ocean University of China (in Chinese with English abstract).

Wei H., L. Wang, Y. A. Lin, and C. S. Chuang, 2002. Nutrient transport across the thermocline in the central Yellow Sea. Advances in Marine Science, 20(3):15-20 (in Chinese with English abstract).

Wei H., J. Shi, Y. Lu, and Y. Peng, 2010. Interannual and long-term hydrographic changes in the Yellow Sea during 1977-1998. Deep-Sea Research Part II, 57(11-12): 1025-1034.

Wei S., and W. M. Jiang, 1992. Study on food web of fishes in the Yellow Sea. Oceanologia Et Limnologia Sinica, 23: 182-192 (in Chinese with English abstract).

Zhao X., J. Hamre, F. Li, X. Jin, and Q. Tang, 2003. Recruitment, sustainable yield and possible ecological consequences of the sharp decline of the anchovy (Engraulis japonicus) stock in the Yellow Sea in the 1990s. Fishery Oceanography, 12(4/5):495-501.

Zhao X. Y., 2006. Population dynamic characteristics and sustainable utilization of the anchovy stock in the Yellow Sea. Doctor Dissertation. Qingdao: Ocean University of China (in Chinese with English abstract).

Zhu D. S., and S. A. Iversen, 1990. Anchovy and other fish resources in the Yellow Sea and East China Sea. Marine Fishery Ressearch, 11: 1-143(in Chinese with English abstract).

Zhuang X. F., H. L. Jiang, and J. Lin, 1997. The relationship between parameters of anchovy body size and their infect on drift net. Fisheries Science, 16(5):26-30 (in Chinese). 


\section{Appendix A. Equations for fish bioenergetics}

\section{Consumption}

Consumption depends on the maximum consumption rate $\left(C_{\max }\right)$, the prey density $(P)$ and the water temperature

(T)

$$
C=C_{\max } \cdot g(P) \cdot h_{C}(T),
$$

where $C_{\max }$ is calculated using an allometric mass function and related to the wet weight $(W)$

$$
C_{\max }=k_{C} \cdot W^{\alpha_{C}},
$$

the intercept $k_{C}$, and the slope $\alpha_{C}$. The factor $g$ is a function of $P$ expressed by

$$
g(P)=\frac{\sum_{i=1}^{2} \frac{P_{m} v_{m}}{k p_{m}}}{1+\sum_{i=1}^{2} \frac{P_{m} v_{m}}{k p_{m}}},
$$

where $m$ denotes the prey type, $P_{m}$ and $k p_{m}$ are the concentration and the half saturation concentration of $m$, respectively, and $v_{m}$ is the vulnerability.

The temperature-dependent function $\left(h_{C}\right)$ is a dome shaped curve, a product of two sigmoid curves as proposed by Thornton and Lessem (1978):

$$
\begin{aligned}
& h_{C}(T)=g c t a \times g c t b, \\
& t t 5=\frac{1}{t e 2_{C}-t e 1_{C}}, \\
& t 5=t t 5 \times \ln \left[\frac{x k 2_{C}\left(1.0-x k 1_{C}\right)}{x k l_{C}\left(1.0-x k 2_{C}\right)}\right], \\
& t 4=e^{\left[t 5\left(T-t e l_{C}\right)\right]}, \\
& t t 7=\frac{1}{t e 4_{C}-t e 3_{C}},
\end{aligned}
$$




$$
\begin{gathered}
t 7=t t 7 \times \ln \left[\frac{x k 3_{C}\left(1.0-x k 4_{C}\right)}{x k 4_{C}\left(1.0-x k 3_{C}\right)}\right], \\
t 6=e^{\left[t 7\left(t e 4_{C}-T\right)\right]}, \\
g c t a=\frac{x k 1_{C} \times t 4}{1.0+x k 1_{C}(t 4-1.0)}, \\
g c t b=\frac{x k 4_{C} \times t 6}{1.0+x k 4_{C}(t 6-1.0)},
\end{gathered}
$$

where $x k 1_{C}, x k 2_{C}, x k 3_{C}$, and $x k 4_{C}$ are the values of the function corresponding to four temperatures, $t e 1_{C}, t e 2_{C}$, $t e 3_{C}$, and $t e 4_{C}$, respectively.

\section{Respiration}

Respiration rate depends on body weight $(W)$, temperature $(T)$ and swimming speed $\left(U_{s}\right)$ as given by

$$
R=k_{R} \cdot W^{\alpha_{R}} \cdot e^{d_{R} U_{s}} \cdot e^{r_{R} T}
$$

where $k_{R}$ is the intercept of the allometric mass function and $\alpha_{R}$ is its slope; $d_{R}$ and $r_{R}$ represent the influences of $T$ and $U_{s}$ on respiration, respectively.

\section{Special dynamic action}

Special dynamic action represents the energy allocated to the food digestive process, and is defined as

$$
S=k_{S}(C-E g)
$$

where $k_{S}$ is the proportion of assimilated energy lost to special dynamic action.

\section{Egestion and excretion}


Egestion is a constant proportion of consumption while excretion is a constant proportion of assimilated energy:

$$
\begin{gathered}
E g=k_{E g} C, \\
E x=k_{E x}(C-E g),
\end{gathered}
$$

where $k_{E g}$ and $k_{E x}$ are the scaling factors for egestion and excretion, respectively.

\section{Appendix B Parameters}

\begin{tabular}{|c|c|c|}
\hline Symbol & Description & Value \\
\hline$k_{c}$ & Intercept for $C_{\max }\left(\mathrm{s}^{-1}\right)$ & $1.57 \times 10^{-6}$ \\
\hline$\alpha_{c}$ & Coefficient for $C_{\max }$ versus weight & -0.256 \\
\hline$t e 1_{C}$ & Temperature for $x k l_{C}\left({ }^{\circ} \mathrm{C}\right)$ & 12 \\
\hline$t e 2_{C}$ & Temperature for $x k 2_{C}\left({ }^{\circ} \mathrm{C}\right)$ & 15 \\
\hline$t e 3_{C}$ & Temperature for $x k 3_{C}\left({ }^{\circ} \mathrm{C}\right)$ & 20 \\
\hline te $4_{C}$ & Temperature for $x k 4_{C}\left({ }^{\circ} \mathrm{C}\right)$ & 30 \\
\hline$x k l_{C}$ & Proportion of $C_{\max }$ at $t e 1_{C}$ & 0.1 \\
\hline$x k 2_{C}$ & Proportion of $C_{\max }$ at $t e 2_{C}$ & 0.9 \\
\hline$x k 3_{C}$ & Proportion of $C_{\max }$ at $t e 3_{C}$ & 0.9 \\
\hline$x k 4_{C}$ & Proportion of $C_{\max }$ at $t e 4_{C}$ & 0.1 \\
\hline$v^{\dagger}$ & Vulnerability of prey to anchovy & $\begin{array}{l}1.0,1.0,1.0,0.5,0.2 \\
0.0,0.0,0.2,0.5,1.0\end{array}$ \\
\hline$k p^{\dagger}$ & $\begin{array}{l}\text { Half saturation constant of prey to anchovy } \\
\left(\mathrm{gW} . \mathrm{W} \cdot \mathrm{prey} / \mathrm{m}^{3}\right)\end{array}$ & $\begin{array}{l}0.1,0.1,0.1,0.1,0.1 \\
0.1,0.1,0.1,0.1,0.1\end{array}$ \\
\hline$k_{R}$ & Intercept for $R\left(\mathrm{~s}^{-1}\right)$ & $2.5 \times 10^{-9}$ \\
\hline$\alpha_{R}$ & Coefficient for $R$ versus $W$ & -0.227 \\
\hline$d_{R}$ & Coefficient for $R$ versus $U_{s}(\mathrm{~s} / \mathrm{m})$ & 5.0 \\
\hline
\end{tabular}

Table 1 Parameters of IBM 


\begin{tabular}{|c|c|c|}
\hline$r_{R}$ & Coefficient for $R$ versus $T\left({ }^{\circ} \mathrm{C}^{-1}\right)$ & 0.0548 \\
\hline$k_{s}^{\dagger \dagger}$ & Coefficient for specific dynamic action & $0.125,0.175,0.175,0.175,0.175$ \\
\hline$k_{E g}^{\dagger \dagger}$ & Proportion of consumed food egested & $0.125,0.16,0.16,0.16,0.16$ \\
\hline$k_{E x}^{\dagger \dagger}$ & Proportion of assimilated energy excreted & $0.078,0.1,0.1,0.1,0.1$ \\
\hline$k_{v}$ & Coefficient for $U_{s}$ versus $L\left(\mathrm{~m} \cdot \mathrm{s}^{-1} \cdot \mathrm{cm}^{-1}\right)$ & 0.03 \\
\hline$r_{v}$ & Coefficient for $U_{s}$ versus $T\left({ }^{\circ} \mathrm{C}^{-1}\right)$ & 0.0548 \\
\hline$T_{s}$ & Cutoff temperature for $U_{s}\left({ }^{\circ} \mathrm{C}\right)$ & 11 \\
\hline$t e 1_{f}^{\dagger \dagger \dagger}$ & Temperature for $x k l_{f}\left({ }^{\circ} \mathrm{C}\right)$ & $7,7,7,7,7,9,12,12,12,12,7,7$ \\
\hline$t e f_{f}^{\dagger \dagger}$ & Temperature for $x k 2_{f}\left({ }^{\circ} \mathrm{C}\right)$ & $11,11,11,12,13,14,20,20,20,20,11,11$ \\
\hline$t e 3_{f}^{\dagger \dagger}$ & Temperature for $x k 3_{f}\left({ }^{\circ} \mathrm{C}\right)$ & $13,13,13,14,16,17,26,26,26,26,13,13$ \\
\hline$t e 4_{f}^{\dagger \dagger \dagger}$ & Temperature for $x k 4_{f}\left({ }^{\circ} \mathrm{C}\right)$ & $15,15,15,16,18,21,30,30,30,30,15,15$ \\
\hline$x k 1_{f}$ & Proportion of food fitness at $t e 1_{f}$ & 0.1 \\
\hline$x k 2_{f}$ & Proportion of food fitness at $t e 2_{f}$ & 0.9 \\
\hline$x k 3_{f}$ & Proportion of food fitness at $t e 3_{f}$ & 0.9 \\
\hline$x k 4_{f}$ & Proportion of food fitness at $t e 4_{f}$ & 0.1 \\
\hline$\alpha^{\dagger \dagger}$ & Natural mortality coefficient $\left(\mathrm{yr}^{-1}\right)$ & $4.44,0.45,0.45,0.92,0.92$ \\
\hline$W s^{\dagger \dagger \dagger}$ & Weight coefficient of spawning & $\begin{array}{l}1.0,5.0,1.0,1.0,1.0 \\
1.0,5.0,1.0,1.0,1.0 \\
1.0,5.0,1.0,1.0,1.0 \\
1.0,5.0,1.0,1.0,1.0 \\
1.0,5.0,1.0,1.0,1.0 \\
1.0,5.0,1.0,1.0,1.0\end{array}$ \\
\hline$a_{s}$ & Parameter in R-SSB relationship & 151.1 \\
\hline$b_{s}$ & Parameter in R-SSB relationship & 0.299 \\
\hline
\end{tabular}

${ }^{\dagger}$ The first row lists values of ZL and the second row values of ZP. The column gives values for one length group of anchovy, the median lengths for those groups being 3.7, 6.0, 9.0, 11.0 and $17.0 \mathrm{~cm}$, respectively.

"Values for the age-0, age-1, age-2, age-3, and age-4 anchovy.

${ }^{\dagger \dagger}$ Values for 12 months.

${ }^{\dagger \dagger}$ Row corresponds to spawning ground and column corresponds to spawning season. 